\title{
Qualidade da cama e do ar em diferentes condições de alojamento de frangos de corte
}

\author{
Thayla Morandi Ridolfi de Carvalho(1), Daniella Jorge de Moura ${ }^{(1)}$, Zigomar Menezes de Souza(1), \\ Gustavo Soares de Souza(1) e Leda Gobbo de Freitas Bueno(1)
}

\begin{abstract}
(1)Universidade Estadual de Campinas, Faculdade de Engenharia Agrícola, Conselho de Infraestrutura Rural, Avenida Candido Rondon, no 501, CEP 13083-875 Campinas, SP. E-mail: thayla.carvalho@feagri.unicamp.br, daniella.moura@feagri.unicamp.br, zigomarms@feagri.unicamp.br, gustavo.souza@feagri.unicamp.br, gobbobueno@gmail.com
\end{abstract}

Resumo - O objetivo deste trabalho foi avaliar as condições iniciais de alojamento de aves, de um dia de idade, em termos da qualidade da cama de frango reutilizada e do ar, em aviários comerciais de produção com diferentes sistemas de ventilação mínima e tipologia, por meio de análise geoestatística. $\mathrm{O}$ experimento foi realizado em quatro aviários: Blue House I (T1) e Blue House II (T2), Dark House (T3) e Convencional (T4). As variáveis analisadas foram: $\mathrm{pH}$, umidade, temperatura superficial e concentração de amônia, tendose coletado as amostras na altura dos frangos, em 80 pontos equidistantes no interior do pinteiro. A análise geoestatística auxiliou a identificação de pontos críticos no controle dos ambientes estudados. O manejo da ventilação mínima não é suficiente para garantir a qualidade do ar nos pinteiros. A cama reutilizada de casca de café e arroz (T1 e T2) apresenta melhor qualidade do que a cama reutilizada de maravalha fina (T3 e T4). O sistema de ventilação mínima, em T2 e T4, é o mais eficiente quanto à renovação do ar nos pinteiros.

Termos para indexação: cama reutilizada, casca de arroz e café, conforto animal, geoestatística, maravalha, sistema de ventilação mínima.

\section{Litter and air quality in different broiler housing conditions}

Abstract - The objective of this work was to assess the initial conditions of poultry housing for one-day-old chicks regarding the quality of reused bedding and of the air in commercial broiler houses with different types of minimum ventilation and typology, using geostatistical analysis. The experiment was carried out in four broiler houses: Blue House I (T1) and Blue House II (T2), Dark House (T3), and Conventional (T4). The following variables were evaluated: $\mathrm{pH}$, moisture, surface temperature, and ammonia concentration, and samples were collected at bird height at 80 equidistant points in the brooding areas. Geostatistical analysis helped to identify the environmental critical control points. The management of minimum ventilation is not sufficient to guarantee air quality in the brooding area. The reused coffee and rice husk beds (T1 and T2) show better quality than the reused wood shaving beds (T3 and T4). The minimum ventilation system, in T2 and T4, is the most efficient regarding air renovation inside the brooding areas.

Index terms: reused bedding, rice and coffee husks, animal comfort, geostatistics, wood shavings, minimum ventilation system.

\section{Introdução}

A cama para aviários apresenta grande impacto na qualidade e na produtividade do frango de corte, sendo um item de importância fundamental para o manejo de galpões em sistemas de produção avícola. A cama tem a função de absorver a umidade, diluir uratos e fezes, fornecer isolamento térmico e proporcionar uma superfície macia para as aves, o que evita a formação de calo no peito e de lesões no coxim plantar, no joelho e no peito (Hernandes \& Cazetta, 2001). Diversos materiais podem ser utilizados como cama de frangos, como, por exemplo, casca de arroz, casca de amendoim, maravalha e papel, entre outros, e devem ser manejados adequadamente para prevenir a proliferação de insetos e para controlar o nível de umidade e amônia, a produção de poeira e a exposição a agentes transmissores de doenças, nos aviários (Hernandes et al., 2002). Segundo Kelleher et al. (2002), a composição da cama, somada aos dejetos, é predominantemente de água e carbono, com menores quantidades de nitrogênio e fósforo e leves traços de cloro, cálcio, magnésio, sódio, manganês, ferro, cobre, zinco e arsênico. A cama de frango varia em sua composição, e as suas características físicas divergem entre os aviários, as granjas e as diferentes regiões (Dao \& Zhang, 2007). Essa variabilidade pode ser atribuída 
às diferenças na quantidade e no tipo de material da cama, no número de lotes de frangos produzidos na cama, no sistema de bebedouros, na quantidade de detritos e no método de limpeza e de armazenamento utilizado.

A reutilização da cama na produção de frangos de corte é uma prática adotada para diminuir custos com a aquisição de camas novas e aumentar a quantidade de nutrientes presentes na cama, para posterior utilização como biofertilizante na agricultura. Também é uma forma de estabilizar ou diminuir o impacto ambiental, ao reduzir a quantidade de camas por ave produzida. No entanto, essa reutilização pode levar a altos níveis de amônia no interior dos galpões, de 60 a 100 ppm, um valor considerado acima do recomendado, que deve ser inferior a 20 ppm (Globalgap, 2007).

Concentrações de amônia no ar acima de 60 ppm tornam as aves mais predispostas a doenças respiratórias, aumentam os riscos de infecções secundárias às vacinas e prejudicam os processos fisiológicos de trocas gasosas (Oliveira et al., 2003). O gás causa ainda estresse aos frangos, o que leva à perda de peso e pode provocar a morte das aves (Hernandes \& Cazetta, 2001).

O nível de umidade da cama é um fator crítico no manejo dos galpões, já que influencia a incidência e a severidade das lesões na carcaça das aves (Qiu \& Guo, 2010) e controla a volatilização da amônia, pois o aumento da umidade promove uma maior liberação de amônia nos galpões de produção (Weaver Junior \& Meijerhof, 1991; Hernandes et al., 2002). O pH da cama também influencia a liberação de amônia, que é minimizada em condição de pH abaixo de 7,0.

É necessário adequar a taxa de ventilação e determinar a emissão de gases poluentes nos aviários, para permitir a melhora do seu ambiente interno (Calvet et al., 2010). A ventilação mínima pode ser definida como a quantidade de ar por unidade de tempo, necessária para manter a qualidade do ar e atender à demanda de oxigênio das aves, ao visar seu bem-estar e sua saúde, sem interferir na temperatura e na sensação térmica das aves.

Há alguns estudos sobre a variabilidade espacial das variáveis relacionadas ao ambiente aéreo e às condições da cama no interior de galpões de produção de frangos de corte (Tasistro et al., 2004; Miles et al., 2006; 2008). Os mapas de variabilidade espacial de dados revelam que a análise de um único ponto de medição deve ser feita com cautela, para que um valor sub ou superestimado não seja relatado como uma condição representante do fenômeno em estudo (Miles et al., 2008).

O objetivo deste trabalho foi avaliar as condições iniciais de alojamento de aves, de um dia de idade, em termos da qualidade da cama de frango reutilizada e do ar em aviários comerciais de produção com diferentes sistemas de ventilação mínima e tipologia, por meio de análise geoestatística.

\section{Material e Métodos}

O experimento foi conduzido em quatro galpões comerciais de frangos de corte: dois localizados em Monte Alegre do Sul, SP $\left(22^{\circ} 40^{\prime} 05^{\prime \prime} \mathrm{S}\right.$ e $46^{\circ} 40^{\prime} 51^{\prime \prime} \mathrm{W}$, a $750 \mathrm{~m}$ de altitude), no inverno de 2008, com os tratamentos Blue House I (T1) e Blue House II (T2); e dois localizados em Mombuca, SP (22 ${ }^{\circ} 55^{\prime} 45^{\prime \prime S}$ e $47^{\circ} 33^{\prime} 58^{\prime \prime} \mathrm{W}$, a $550 \mathrm{~m}$ de altitude), no inverno de 2009, com os tratamentos Dark House (T3) e Convencional (T4). O clima nas duas localidades, conforme a classificação de Köppen, é do tipo Cwa, mesotérmico, com inverno seco.

As dimensões dos galpões T1 e T2 eram de 22x90x3 e $9 \times 125 \times 3,25 \mathrm{~m}$, respectivamente, ambos com orientação leste-oeste e sistema de ventilação mínima com dois exaustores VA-130 (50") Casp (Avicasp, Toledo, PR), com 1,00 CV, seção circular de diâmetro de $1,30 \mathrm{~m}$ e vazão de $38.000 \mathrm{~m}^{3}$ por hora, que eram acionados durante $50 \mathrm{~s}$ a cada $5 \mathrm{~min}$. Os galpões do tipo Blue House apresentam cortinas na cor azul, para controlar a iluminância e, consequentemente, a atividade das aves. Os forros, na altura do pé direito, eram de polietileno, na cor azul, e as laterais eram teladas e protegidas por duplo cortinado de polietileno, da mesma cor. Os galpões tinham face externa de material laminado, muretas de $0,50 \mathrm{~m}$ e cobertura de telhas de fibrocimento. O sistema de ventilação utilizado foi do tipo túnel, com entrada de ar pelas aberturas na face oposta aos exaustores do aviário (T1) ou pelas laterais da face oposta aos exaustores (T2). Já o sistema de aquecimento, era operado por aquecedores manuais à lenha, posicionados no centro do pinteiro, com distribuição por tubos metálicos e acionamento feito de forma manual, tendo-se considerado a temperatura aferida pelos sensores do controlador, para alcançar temperatura de bulbo seco entre 32 e $33^{\circ} \mathrm{C}$; entretanto, o T1 alcançou média de 
$25,3^{\circ} \mathrm{C}$ e o $\mathrm{T} 2$ de $25,6^{\circ} \mathrm{C}$. A densidade de aves era de 17 aves por metro quadrado, para T1, que é considerada ideal de acordo com o Manual de Frango de Corte desta linhagem, o que exige densidade máxima de 16,8 aves por metro quadrado; e de 16 aves por metro quadrado para T2 que é considerada acima do ideal, o que requer densidade máxima de 12,8 aves por metro quadrado. Nos dois casos foi utilizada a linhagem Cobb-Vantress 500.

Os galpões T3 e T4 apresentavam dimensões de $18 \times 120 \times 3$ e 12x120x3,5 m, respectivamente, com orientação leste-oeste e sistema de ventilação mínima com dois exaustores do tipo axial WF5015TCP (50") (Munters, Curitiba, PR), com 1,50 CV, seção circular de diâmetro de $1,30 \mathrm{~m}$ e vazão de $40.000 \mathrm{~m}^{3}$ por hora, que eram acionados durante $50 \mathrm{~s}$ a cada $5 \mathrm{~min}$. A entrada de ar era pela laterais, para T3, e por manejo lateral das cortinas para T4. O aquecimento foi feito por meio de aquecedores automáticos a diesel, posicionados no centro do pinteiro, com tubo aquecedor para alcançar a temperatura de bulbo seco entre 32 e $33^{\circ} \mathrm{C}$; contudo, o T3 alcançou média de $19,7^{\circ} \mathrm{C}$ e o T4 de $19,9^{\circ} \mathrm{C}$. Os dois galpões eram cobertos com telhas de fibrocimento. No sistema de criação Dark House, as aves são submetidas a uma intensidade luminosa e a um fotoperíodo controlados por cortinas pretas. $\mathrm{O}$ forro era de material laminado preto na face inferior e laminado nas faces superiores e externas, a 3,0 m de altura, e as laterais eram teladas e protegidas por duplo cortinado de polietileno na cor preta; as muretas eram de $0,40 \mathrm{~m}$. Com o ambiente totalmente controlado por exaustores e o uso de resfriamento evaporativo de forma ideal, espera-se que o nível de estresse das aves seja reduzido significativamente e que a imunidade ativa do animal aumente (Gallo, 2009). No aviário do tipo Convencional, utiliza-se o sistema de ventilação mínima por manejo de cortinas, normalmente na cor amarela. Esse tipo de aviário não apresenta isolamento igual aos demais, o que permite que o ambiente externo influencie o ambiente interno do galpão. A densidade de aves era de 15 aves por metro quadrado, para T3, que é considerada ideal segundo o Manual de Frango de Corte desta linhagem, o que requer densidade máxima de 16,8 aves por metro quadrado; e de 14 aves por metro quadrado, para T4, que é considerada acima do ideal, o que exige densidade máxima de 12,0 aves por metro quadrado. Nos dois casos foi utilizada a linhagem Cobb-Vantress 500.
As aves, de um ano de idade, foram alojadas em cama de casca de arroz e de café, com profundidade de 0,10 m (50:50), na segunda utilização, em T1 e T2, e de maravalha fina, com profundidade de $0,10 \mathrm{~m}$, na segunda utilização, em T3 e T4. Todas as camas foram tratadas pelo sistema de fermentação e enleiradas no centro do aviário. A avaliação da cama de frango foi realizada de acordo com a qualidade da cama do aviário inerente ao ambiente gerado, com base nas variáveis de $\mathrm{pH}$ e umidade. A temperatura da cama foi monitorada com um termômetro de superfície a laser Omegascope modelo 05520 (Stamford, Connecticut, EUA). O pH foi determinado com um pHmetro digital PM608, (ANALION, Ribeirão Preto, SP). Aumidade da cama foi determinada pelo método recomendado pelo Ministério da Agricultura (Brasil, 1992), conforme a equação:

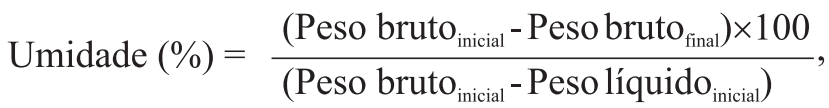

em que o peso bruto inicial é o peso da cama de frango antes de ser colocada na estufa por 24 horas a $105^{\circ} \mathrm{C}$, com o peso do cadinho; o peso bruto final é o peso da cama após ser colocada na estufa; e o peso líquido inicial é o peso da cama de frango antes de ser colocada na estufa.

O monitoramento do ambiente aéreo foi realizado, ao medir-se a concentração de amônia na altura das aves, por um medidor de gás GasAlertMIcro 5, (BW Technologies, Jundiaí, SP).

As amostras foram coletadas às $9 \mathrm{~h}$, em 80 pontos equidistantes no interior dos pinteiros (os dados foram registrados apenas na área ocupada pelas aves), no dia do alojamento das aves, pois esse momento é decisivo para o bom desenvolvimento do lote, além de ser considerado crítico para o arranque inicial das aves. As dimensões dos pinteiros eram de $22 \times 30,9 \times 40$, $18 \times 50$ e 12x55 m para os tratamentos T1, T2, T3 e T4, respectivamente. Os pinteiros estavam localizados no centro dos aviários.

A variabilidade dos parâmetros em estudo foi avaliada pela análise exploratória dos dados, tendo-se calculado a média, a mediana, o desvio padrão, o coeficiente de variação, o coeficiente de assimetria e o coeficiente de curtose, para se obter os valores máximos e mínimos (SAS Institute, 2002). A observação dos valores extremos e a distribuição de frequência indicam a existência de valores atípicos 
em relação às variáveis em estudo. Portanto, optou-se pela reedição dos dados extremos, pela média de seus vizinhos.

Os dados foram submetidos à análise geoestatística, tendo-se assumido as pressuposições da hipótese intrínseca. $\mathrm{O}$ semivariograma experimental foi estimado pela equação (Vieira, 2000):

$$
\hat{\gamma}=\frac{1}{2 \mathrm{~N}(\mathrm{~h})} \sum_{\mathrm{i}=1}^{\mathrm{N}(\mathrm{h})}\left[\mathrm{Z}\left(\mathrm{x}_{1}\right)-\mathrm{Z}\left(\mathrm{x}_{1}+\mathrm{h}\right)\right]^{2},
$$

em que $\mathrm{N}(\mathrm{h})$ é o número de pares experimentais de observações $Z\left(x_{i}\right)$ e $Z\left(x_{i}+h\right)$, separados por uma distância h. O semivariograma é representado pelo gráfico $\hat{\gamma}(\mathrm{h})$ versus $\mathrm{h}$. A partir do ajuste de um modelo matemático aos valores calculados de $\hat{\gamma}(\mathrm{h})$, foram estimados os coeficientes do modelo teórico para o semivariograma (efeito pepita, $\mathrm{C}_{0}$; patamar, $\mathrm{C}_{0}+\mathrm{C}_{1}$; e alcance, a). Para analisar o grau da dependência espacial dos atributos em estudo, utilizou-se a classificação de Cambardella et al. (1994), em que os semivariogramas são considerados como de dependência espacial forte, moderada e fraca quando têm um efeito pepita $<25 \%$, entre 25 e $75 \%$, e acima de $75 \%$ do patamar, respectivamente.
Foram considerados os modelos de semivariogramas esférico, exponencial, linear e gaussiano, ajustados pelo programa $\mathrm{GS}^{+}$(Robertson, 2008); posteriormente, esses modelos foram utilizados para o desenvolvimento de mapas de isolinhas (krigagem). Em caso de dúvida entre mais de um modelo para o mesmo semivariograma, considerou-se o maior valor do coeficiente de correlação obtido pelo método de validação cruzada. Para a elaboração dos mapas de distribuição espacial das variáveis, foi utilizado o programa Surfer (Golden Software, 2009).

\section{Resultados e Discussão}

O sistema de ventilação mínima não foi eficiente para a renovação de ar, em T1 e T3, pois a concentração de amônia (Tabela 1) apresentou valores médios iguais a 57,9 e $36,1 \mathrm{ppm}$, respectivamente, ambos acima do limite ideal (20 ppm) preconizado por Globalgap (2007), Manning et al. (2007) e Cobb-Vantress Brasil (2008). Foram observados valores do $\mathrm{pH}$ da cama próximos de 5,5, o que auxilia no processo de não degradação bioquímica do ácido úrico presente na cama e na produção de amônia (Elliot \& Collins, 1982), mesmo quando a umidade da cama está abaixo de $35 \%$, valor considerado dentro

Tabela 1. Estatísticas das variáveis concentração de amônia no ar (ppm), temperatura da cama $\left({ }^{\circ} \mathrm{C}\right)$, $\mathrm{pH}$ da cama e umidade da cama (\%) para os tratamentos T1, T2, T3 e T4.

\begin{tabular}{|c|c|c|c|c|c|c|c|c|}
\hline Variável & Média & Mediana & Mínimo & Máximo & Desvio-padrão & $\mathrm{CV}(\%)$ & Curtose & Assimetria \\
\hline & \multicolumn{8}{|c|}{ Blue House I (T1) } \\
\hline Amônia & 57,9 & 58,5 & 39,0 & 68,0 & 5,9 & 10,2 & 0,4 & $-0,8$ \\
\hline Temperatura & 27,2 & 27,0 & 22,0 & 34,0 & 2,1 & 7,7 & 1,5 & 0,6 \\
\hline $\mathrm{pH}$ & 5,7 & 5,6 & 5,1 & 6,7 & 0,4 & 6,4 & 0,6 & 1,0 \\
\hline \multirow[t]{2}{*}{ Umidade } & 25,6 & 22,1 & 10,0 & 41,3 & 7,9 & 30,7 & $-1,0$ & 0,5 \\
\hline & \multicolumn{8}{|c|}{ Blue House II (T2) } \\
\hline Amônia & 2,5 & 3,0 & 2,0 & 4,0 & 0,5 & 20,9 & $-1,4$ & 0,2 \\
\hline Temperatura & 25,3 & 25,0 & 22,0 & 31,0 & 2,0 & 7,9 & $-0,2$ & 0,5 \\
\hline $\mathrm{pH}$ & 5,6 & 5,6 & 4,3 & 8,4 & 0,6 & 9,9 & 7,8 & 1,3 \\
\hline \multirow[t]{2}{*}{ Umidade } & 26,5 & 22,1 & 10,0 & 46,6 & 8,6 & 32,4 & $-1,0$ & 0,4 \\
\hline & \multicolumn{8}{|c|}{ Dark House (T3) } \\
\hline Amônia & 36,1 & 39,0 & 10,0 & 44,0 & 7,5 & 20,8 & 2,5 & $-1,6$ \\
\hline Temperatura & 27,0 & 27,0 & 23,0 & 33,0 & 2,5 & 9,2 & $-0,6$ & 0,4 \\
\hline $\mathrm{pH}$ & 8,3 & 8,4 & 7,2 & 8,8 & 0,3 & 3,6 & 3,1 & $-1,4$ \\
\hline \multirow[t]{2}{*}{ Umidade } & 16,9 & 16,3 & 12,0 & 26,0 & 3,3 & 19,3 & 0,6 & 0,9 \\
\hline & \multicolumn{8}{|c|}{ Convencional (T4) } \\
\hline Amônia & 6,3 & 6,0 & 4,0 & 8,0 & 1,4 & 23,0 & $-1,4$ & $-0,1$ \\
\hline Temperatura & 23,7 & 23,0 & 19,0 & 34,0 & 3,5 & 14,6 & 0,9 & 1,1 \\
\hline $\mathrm{pH}$ & 7,6 & 7,5 & 6,8 & 8,5 & 0,4 & 5,9 & $-0,8$ & 0,3 \\
\hline Umidade & 18,0 & 18,1 & 11,8 & 23,9 & 3,2 & 17,5 & $-1,0$ & $-0,1$ \\
\hline
\end{tabular}


dos parâmetros ideais (Cobb-Vantress Brasil, 2008). Assim, as altas concentrações de amônia podem ser atribuídas à reutilização da cama (Gonzáles \& Saldanha, 2001), e, principalmente, à maior relação volume de ar renovado/número de exaustores, o que dificulta a renovação do ar por meio da ventilação mínima, nesses galpões. Outro fator que contribuiu para maiores concentrações de amônia, em T1 e T3, foi a densidade das aves, pois haviam 28.800 aves alojadas em T1 e 32.400 aves alojadas em T3, o que representa 12.240 aves a mais em relação ao T4. Os tratamentos T2 e T4 apresentaram manejo da ventilação adequado, o que possibilitou concentrações de amônia de 3,0 e 6,0 ppm, respectivamente, considerados ideais para a produção de frangos de corte.

A temperatura superficial da cama (Tabela 1), para os tratamentos T2 e T4, apresentou média igual a 25,3 e $23,7^{\circ} \mathrm{C}$, respectivamente, o que mostra que o aquecimento do ar não foi realizado adequadamente para permitir o aquecimento da cama. Os valores em $\mathrm{T} 1$ e $\mathrm{T} 3$, de 27,2 e $27,0^{\circ} \mathrm{C}$, respectivamente, encontravam-se de acordo com o intervalo adequado para o alojamento de aves de um dia de idade, isto é, entre 27 e $32^{\circ} \mathrm{C}$ (Cobb-Vantress Brasil, 2008). Miles et al. (2008) verificaram valores de temperatura de 24 a $42^{\circ} \mathrm{C}$, em sistemas de produção de frango de corte, com dois dias de alojamento.

$\mathrm{O} \mathrm{pH}$ foi influenciado pelo tipo de matéria prima da cama, tendo apresentado comportamento semelhante para os tratamentos T1 e T2, com camas constituídas de casca de café e arroz, e para T3 e T4, constituídas de maravalha fina. A umidade também foi influenciada pelo material que compõe a cama.

As medidas de tendência central apresentaram-se próximas. Isso indica que o conjunto de dados das variáveis não foi influenciado por valores extremos (Cambardella et al., 1994), o que poderia interferir nas análises, inclusive na análise geoestatística (Cressie, 1993). Os valores de curtose e assimetria mostram que a maioria das variáveis apresentou proximidade à distribuição normal, o que é preferível para a análise geoestatística, mas não é exigência para a análise de semivariogramas (Cressie, 1993).

De acordo com a classificação do coeficiente de variação (Warrick \& Nielsen, 1980), a concentração de amônia para $\mathrm{T} 1$, a temperatura para $\mathrm{T} 1$, T2 e $\mathrm{T} 3$, e o $\mathrm{pH}$ nos quatro tratamentos apresentaram baixa variabilidade $(\mathrm{CV}<12 \%)$; os valores para temperatura, umidade, $\mathrm{pH}$ e concentração de amônia relativos aos demais tratamentos apresentaram

Tabela 2. Modelos e parâmetros dos semivariogramas para as variáveis concentração de amônia no ar (ppm), temperatura da cama $\left({ }^{\circ} \mathrm{C}\right), \mathrm{pH}$ da cama e umidade da cama $(\%)$ para os tratamentos $\mathrm{T} 1, \mathrm{~T} 2, \mathrm{~T} 3$ e T4.

\begin{tabular}{|c|c|c|c|c|c|c|c|}
\hline Variável & Modelo & $\mathrm{EP}^{(1)}$ & Patamar & Alcance & $\mathrm{GDE}^{(2)}$ & $\mathrm{R} 2^{(3)}$ & $\mathrm{SQR}^{(4)}$ \\
\hline & \multicolumn{7}{|c|}{ Blue House I (T1) } \\
\hline Amônia & Esférico & 0,20 & 44,05 & 18,1 & 0,5 & 95,1 & $8,42 \times 10$ \\
\hline Temperatura & Esférico & 0,01 & 4,62 & 7,9 & 0,2 & 91,8 & 1,73 \\
\hline $\mathrm{pH}$ & Exponencial & 0,07 & 0,15 & 13,2 & 48,0 & 91,6 & $1,86 \times 10^{-4}$ \\
\hline \multirow[t]{2}{*}{ Umidade } & Esférico & 29,0 & 65,22 & 3,3 & 44,5 & 91,5 & $1,43 \times 10$ \\
\hline & \multicolumn{7}{|c|}{ Blue House II (T2) } \\
\hline Amônia & Esférico & 0,003 & 0,286 & 5,8 & 1,0 & 93,1 & $1,16 \times 10^{-3}$ \\
\hline Temperatura & Esférico & 1,2 & 4,74 & 11,1 & 35,3 & 96,6 & $2,13 \times 10^{-1}$ \\
\hline $\mathrm{pH}$ & $\mathrm{EPP}^{(5)}$ & - & - & - & - & - & - \\
\hline \multirow[t]{2}{*}{ Umidade } & Exponencial & 40,0 & 75,69 & 5,4 & 52,8 & 54,5 & $6,94 \times 10$ \\
\hline & \multicolumn{7}{|c|}{ Dark House (T3) } \\
\hline Amônia & Esférico & 6,2 & 61,44 & 18,4 & 10,1 & 98,0 & $3,14 \times 10$ \\
\hline Temperatura & Esférico & 0,01 & 9,89 & 29,3 & 0,1 & 97,0 & 3,19 \\
\hline $\mathrm{pH}$ & Esférico & 0,019 & 0,106 & 14,6 & 18,3 & 94,0 & $1,65 \times 10^{-4}$ \\
\hline \multirow[t]{2}{*}{ Umidade } & Esférico & 0,32 & 13,55 & 14,6 & 2,4 & 91,4 & $1,03 \times 10$ \\
\hline & \multicolumn{7}{|c|}{ Convencional (T4) } \\
\hline Amônia & Gaussiano & 0,01 & 6,03 & 53 & 0,5 & 98,5 & 1,14 \\
\hline Temperatura & Esférico & 1,6 & 11,55 & 9,7 & 13,9 & 82,7 & 3,82 \\
\hline $\mathrm{pH}$ & Esférico & 3,38 & 22,03 & 9,2 & 15,3 & 81,9 & $1,39 \times 10$ \\
\hline Umidade & Exponencial & 2,45 & 12,33 & 33,5 & 19,9 & 85,4 & $1,0 \times 10$ \\
\hline
\end{tabular}

${ }^{(1)} \mathrm{EP}$, efeito pepita. ${ }^{(2)} \mathrm{GDE}$, grau de dependência espacial. ${ }^{(3)} \mathrm{R}^{2}$, coeficiente de determinação. ${ }^{(4)} \mathrm{SQR}$, soma de quadrados do resíduo. ${ }^{(5)} \mathrm{EPP}$, efeito pepita puro. 
variação moderada $(12<\mathrm{CV}<24 \%)$; e a umidade da cama para T1 e T2 apresentou alta variação (CV>24\%) (Tabela 2).

As variáveis em estudo apresentaram dependência espacial, caracterizada pelo ajuste dos modelos teóricos de semivariogramas. A exceção foi $\mathrm{o} \mathrm{pH}$, no T2, que apresentou efeito pepita puro (Tabela 2), característica da ausência de dependência espacial, em que a variabilidade é associada ao efeito aleatório, ou seja, à independência das amostras (Vieira, 2000). Os modelos esférico, exponencial e gaussiano (Figura 1) foram os que melhor se ajustaram aos dados experimentais em relação aos modelos testados e apresentaram menor soma de quadrados do resíduo e maior coeficiente de determinação, o que torna a estimativa dos parâmetros do modelo e a interpolação dos dados mais confiáveis.

$\mathrm{O} \mathrm{C}_{0}$ é o valor de semivariância dos dados quando $\mathrm{h}=0$ e representa a variabilidade aleatória dos dados, que não é detectada pela escala de amostragem (Cambardella et al., 1994). A relação $\mathrm{C}_{0} /\left(\mathrm{C}_{0}+\mathrm{C}_{1}\right) * 100$, que caracteriza o grau de dependência espacial (GDE), foi classificada como moderada $(25<\mathrm{GDE}<75 \%)$, para pH no T1 e para umidade no T1 e no T2, e como forte $(\mathrm{GDE}<25 \%)$ para as demais variáveis de temperatura, umidade e $\mathrm{pH}$ da cama e para a concentração de amônia nos seus respectivos tratamentos (Cambardella et al., 1994). Quanto menor for o efeito aleatório $\left(\mathrm{C}_{0}\right)$ na variabilidade dos dados, maior será a proporção da variabilidade associada à dependência espacial e melhores as estimativas na interpolação dos dados, o

Blue House I (T1)
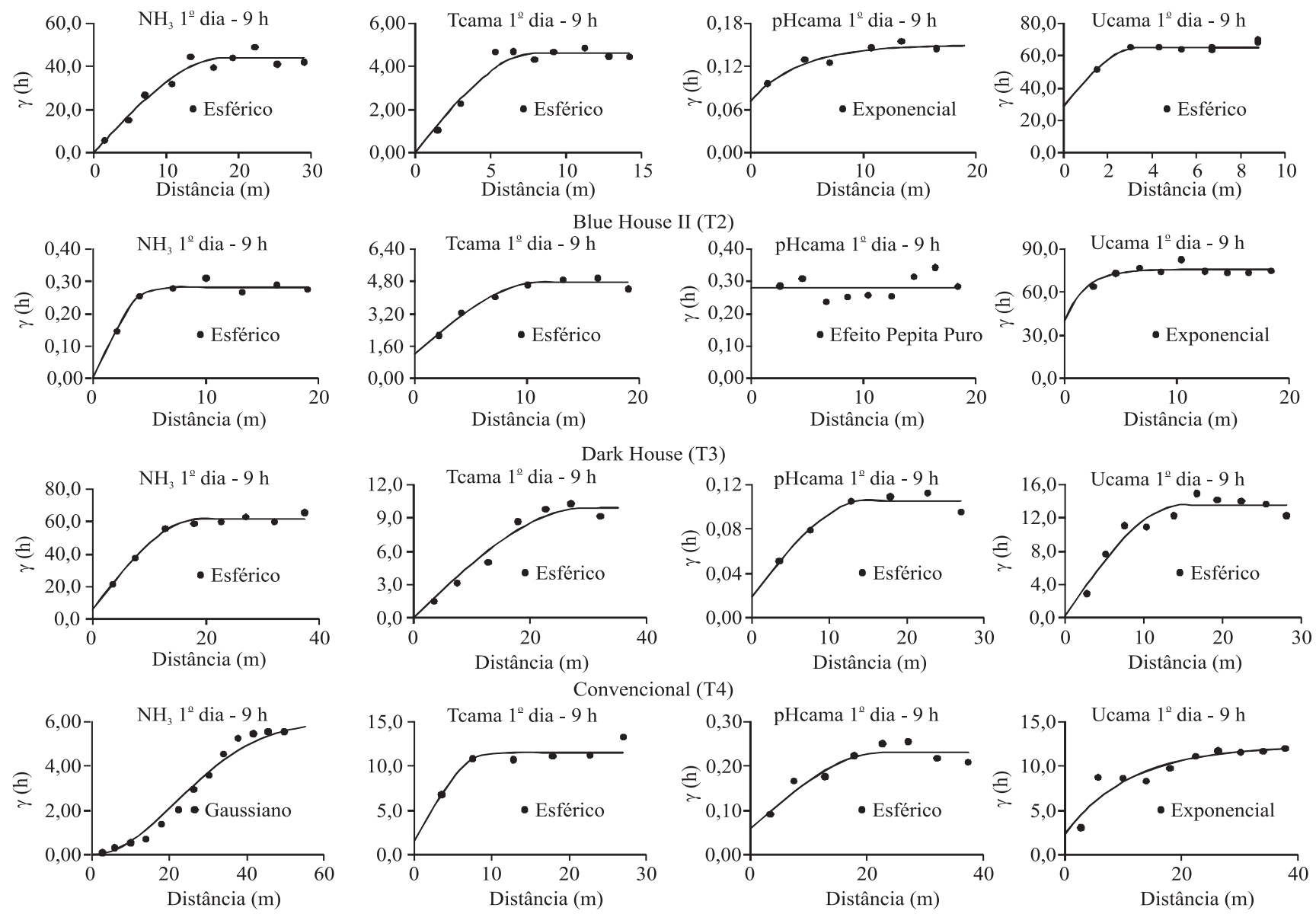

Figura 1. Semivariogramas experimentais e modelos ajustados para as variáveis concentração de amônia no ar $\left(\mathrm{NH}_{3}\right)$, temperatura da cama (Tcama), $\mathrm{pH}$ da cama (pHcama) e umidade da cama (Ucama) para os tratamentos Blue House I (T1); Blue House II (T2); Dark House (T3); Convencional (T4). 
que permite produzir mapas que representam com maior precisão a realidade do fenômeno (Vieira, 2000).

O alcance das variáveis em estudo ficou entre 3,3 e 33,5 m. As amostras separadas por distâncias menores que o alcance apresentam relação de dependência espacial, enquanto as amostras separadas por distâncias maiores não apresentam essa relação (Cambardella et al., 1994).

A Figura 2 apresenta a distribuição da concentração de amônia para os quatro tratamentos em estudo. Foram

Concentração de amônia (ppm)

$\mathrm{T} 1$

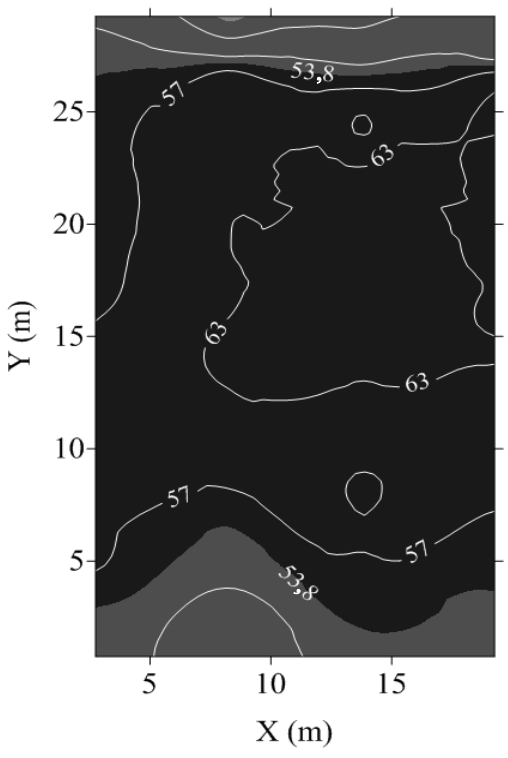

$\mathrm{T} 1$

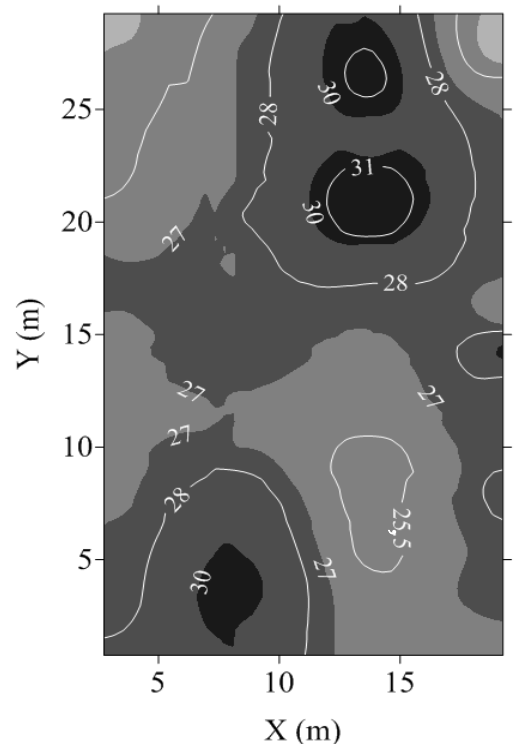

$\mathrm{T} 2$

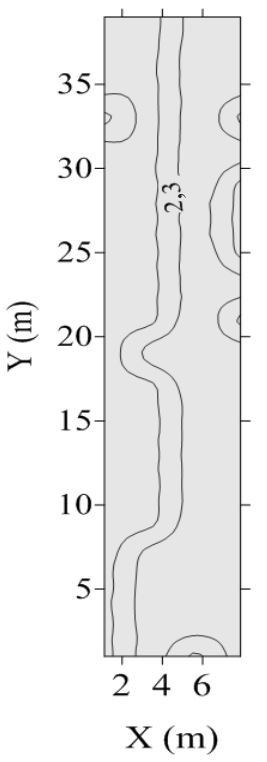

Temperatura superficial da cama $\left({ }^{\circ} \mathrm{C}\right)$

$\mathrm{T} 2$

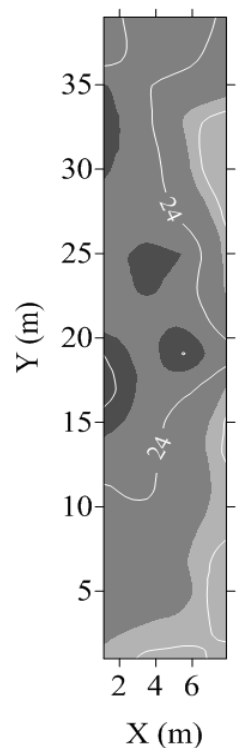

$\mathrm{T} 3$

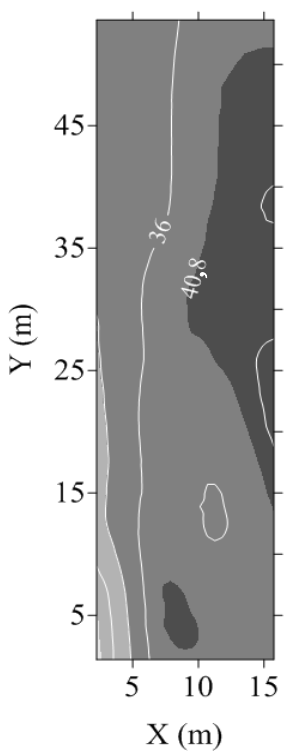

$\mathrm{T} 3$

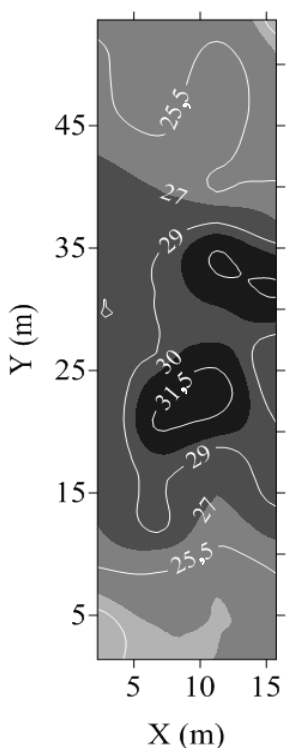

$\mathrm{T} 4$
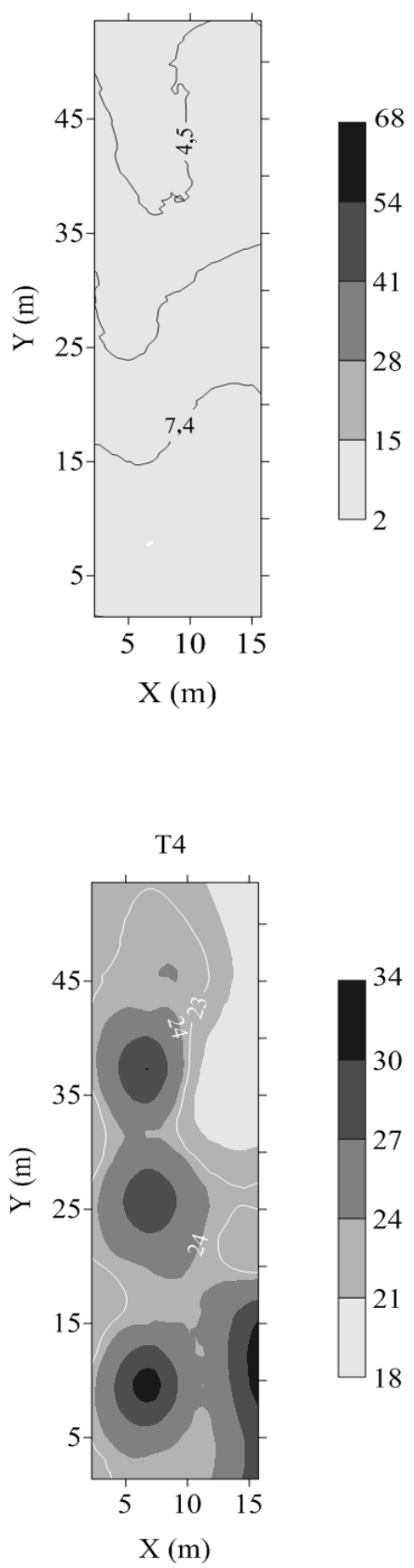

Figura 2. Distribuição espacial da concentração de amônia no ar (ppm) e da temperatura da cama $\left({ }^{\circ} \mathrm{C}\right)$ para os tratamentos Blue House I (T1), Blue House II (T2), Dark House (T3) e Convencional (T4). X e Y, distância (m). 
observados maiores valores $(63,0 \mathrm{ppm})$ no centro do pinteiro de $\mathrm{T} 1$, seguidos de elevados valores $(40,8$ ppm) na lateral direita para o T3. Esse resultado pode ser atribuído à relação entre o número de exaustores acionados no momento do registro dos dados e ao volume de ar a ser renovado no pinteiro (T1: dois exaustores acionados para renovar $1.980 \mathrm{~m}^{3} \mathrm{de}$ ar; $\mathrm{T} 2$ : dois exaustores acionados para renovar $1.170 \mathrm{~m}^{3} \mathrm{de}$ ar; e T3: dois exaustores acionados para renovar 2.700 $\mathrm{m}^{3}$ de ar). Portanto, há a necessidade de acionar mais exaustores para o T1 e o T3, para possibilitar uma renovação de ar adequada, como ocorreu no T2; o T4 apresentou concentrações de amônia menores, em decorrência do menor isolamento deste tipo de aviário, que sofre influência do ambiente externo. Esses resultados indicam manejo da ventilação mínima inadequado e não homogêneo.

O Brasil não possui limites legais de exposição de aves à amônia; porém, exportadores de carne de frango adotam o limite máximo de $20 \mathrm{ppm}$. Entretanto, as concentrações de amônia em sistemas de produção intensivo fechado, como os galpões T1 e T3, podem apresentar valores de até $50 \mathrm{ppm}$ na última semana de produção, que são considerados muito acima do limite ideal (Jones et al., 2005; Owada et al., 2007).

A temperatura superficial da cama (Figura 2) apresentou maiores valores na proximidade dos aquecedores, como verificado em T4, que tem uma fornalha à lenha dentro de cada círculo de proteção. No T4, foram observadas menores temperaturas na região próxima às cortinas laterais à direita, o que indica que o isolamento deveria ser maior para melhorar a homogeneidade da temperatura. O mesmo ocorreu em T2, tratamento que também utiliza o manejo de cortinas para a ventilação mínima.

Em T1 e T3, foram observados os maiores valores de temperatura superficial da cama, mensurados no interior do pinteiro, que foram superiores a $30^{\circ} \mathrm{C}$. Esse resultado pode ser explicado pela maior eficiência do aquecimento e pelo maior isolamento dos aviários, pois não é utilizado o manejo de cortinas. A temperatura da cama apresentou maiores valores em T1, quando havia maior densidade de frangos do que nos outros aviários, o que concorda com os resultados obtidos por Oliveira et al. (2000). $\mathrm{O}$ maior isolamento térmico proporciona às aves um maior consumo de ração e ganho de peso e uma melhor conversão alimentar (Oliveira et al., 2000).

A distribuição espacial do $\mathrm{pH}$ da cama variou entre 5,25 e 8,6 (Figura 3). Em condições de umidade excessiva, a cama pode produzir amônia a partir do metabolismo microbiano sobre as excretas. A amônia produzida, ao se desprender, pode propiciar o aparecimento de lesões respiratórias e oculares nas aves. Assim, a reutilização da cama pode levar a altos níveis de amônia em galpões (60 a 100 ppm), até mesmo nos primeiros dias de criação do lote (Gonzáles \& Saldanha, 2001). Portanto, a amônia pode se tornar problemática, principalmente no inverno, em decorrência das condições de umidade excessiva da cama, o que propicia o crescimento de agentes patogênicos (Avila et al., 1992). Valores de $\mathrm{pH}$ superiores a 7,0 normalmente estimulam a proliferação bacteriana na cama e também aumentam a produção de amônia (Traldi et al., 2007).

Houve maior variabilidade da distribuição da umidade da cama de frango em T1 e T2 do que em T3 e T4 (Figura 3). A maior homogeneidade em T3 pode ser atribuída ao maior controle das variáveis climáticas no galpão Dark House, por apresentar maior isolamento. Os pontos específicos, com altos valores de umidade em T1 $(41,3 \%)$ e T2 $(46,6 \%)$, representados pela cor preta (acima de 35\%), podem indicar vazamento de água nos bebedouros do tipo "nipple" (Figura 3). As aves criadas em maior densidade sofrem maior estresse térmico e, consequentemente, bebem mais água e eliminam mais água nas suas excretas, o que aumenta o teor de umidade da cama (Oliveira et al., 2000). Outro fator que pode ter influenciado os resultados foi a diferença de densidade de alojamento das aves e o poder de absorção de umidade dos diferentes tipos de cama - a cama de maravalha absorve melhor a umidade existente nas fezes. Segundo Araújo et al. (2007), a densidade populacional também deve ser considerada na produção de frangos de corte, pois o excesso de animais por área pode ocasionar estresse com consequente baixo desempenho, enquanto a subutilização de área pode afetar o retorno dos investimentos nas instalações.

Em relação à qualidade da cama, o T1 mostrouse mais adequado; entretanto, foi o tratamento que apresentou maior concentração de amônia, resultado 
de um sistema de ventilação mínima ineficiente quanto à renovação do ar. Já os tratamentos T2 e T4, apresentaram sistema de ventilação mais adequado, o que resultou em uma melhor qualidade do ar. Diversos fatores interferem na liberação de amônia em galpões de produção; contudo, um melhor conhecimento dessas variáveis possibilita a adoção de um manejo mais adequado da cama para se conseguir uma maior produtividade de frangos de corte (Hernandes et al., 2002).

Potencial hidrogeniônico da cama

$\mathrm{T} 1$

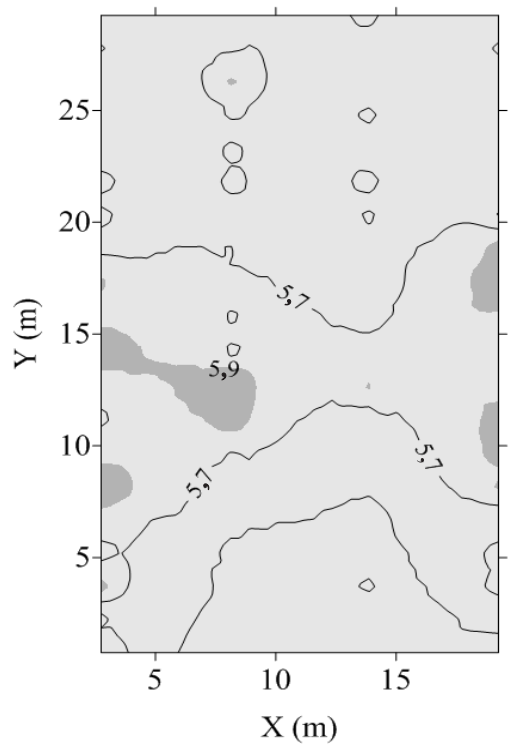

T3

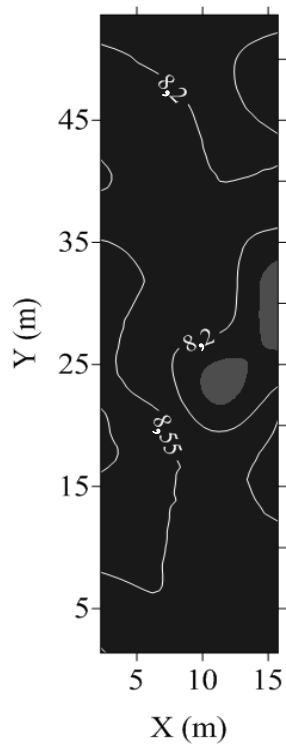

T4

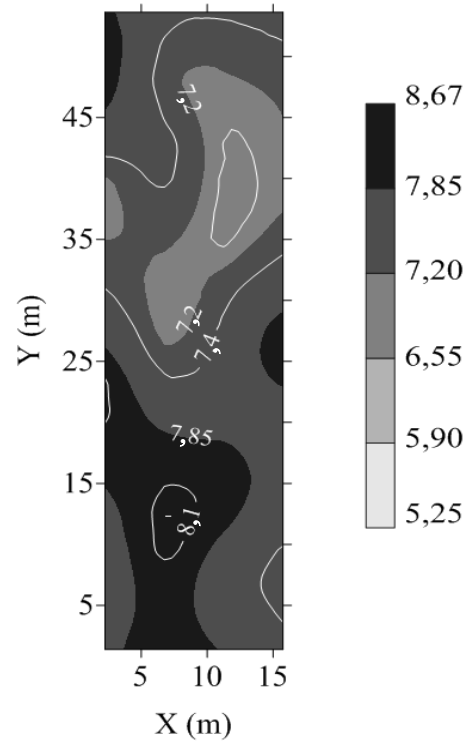

Umidade da cama $(\%)$

$\mathrm{T} 1$

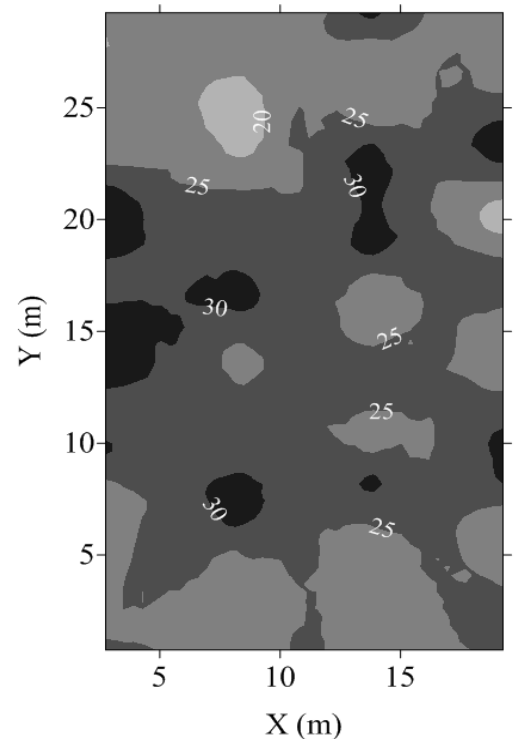

$\mathrm{T} 2$

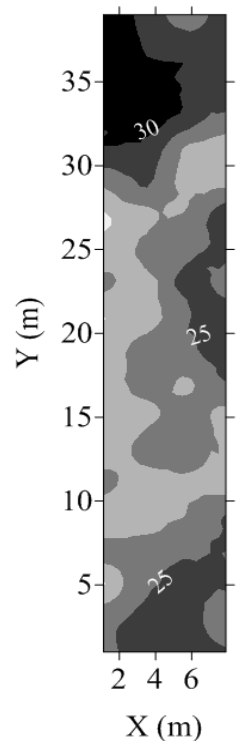

T3

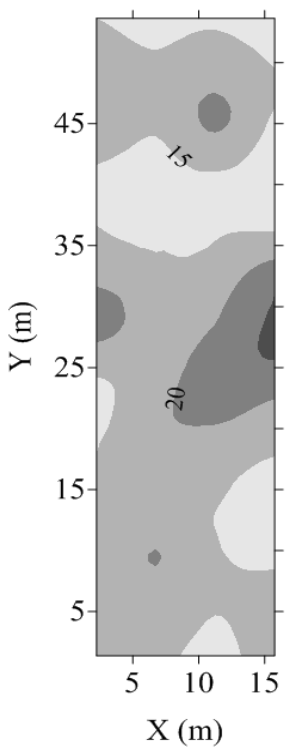

$\mathrm{T} 4$

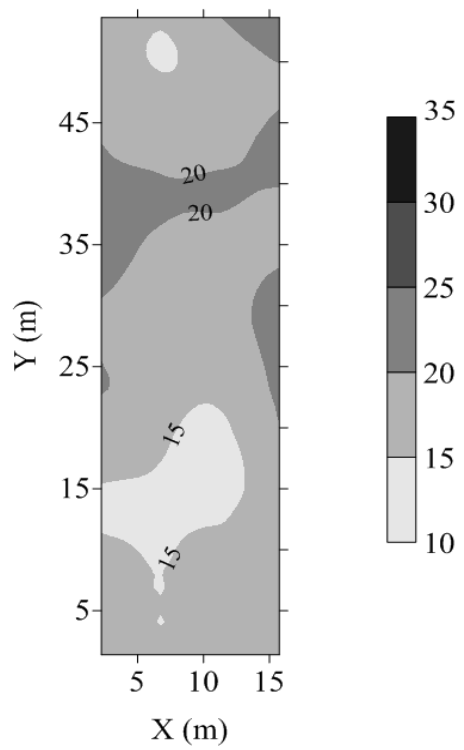

Figura 3. Distribuição espacial do pH da cama e da umidade da cama (\%) para os tratamentos Blue House I (T1), Blue House II (T2), Dark House (T3) e Convencional (T4). X e Y, distância (m). 


\section{Conclusões}

1. A análise geoestatística auxilia a identificação de regiões problemáticas no interior do pinteiro, o que permite adequar o manejo da ventilação mínima às condições relacionadas à qualidade da cama de frango.

2. A cama constituída de casca de café e arroz apresenta melhor qualidade em termos de $\mathrm{pH}$ e umidade, pelo tipo de material utilizado, além de valores de acordo com os limites ideais para a produção de frangos de corte.

3. O manejo da ventilação mínima não é suficiente para garantir a qualidade do ar no primeiro dia de vida das aves para os galpões T1 e T3, em decorrência da maior relação volume de ar renovado/exaustores somada à densidade de aves, nestes aviários.

4. É necessário intensificar o sistema de aquecimento nos quatro tratamentos, para assegurar que a temperatura superficial da cama de frango seja ideal para receber os pintinhos.

5. Os sistemas de ventilação mínima utilizados em T2 e T4 são os mais eficientes em termos de renovação do ar, o que resulta em uma melhor qualidade do ar.

\section{Referências}

ARAÚJO, J. dos S.; OLIVEIRA, V. de; BRAGA, G.C. Desempenho de frangos de corte criados em diferentes tipos de cama e taxa de lotação. Ciência Animal Brasileira, v.8, p.59-64, 2007.

AVILA, V.S. de; MAZZUCO, H.; FIGUEIREDO, E.A.P. de. Cama de aviário: materiais, reutilização, uso como alimento e fertilizante. Concórdia: Embrapa-CNPSA, 1992. 38p. (Embrapa-CNPSA. Circular técnica, 16).

BRASIL. Ministério da Agricultura e Reforma Agrária. Regras para análise da qualidade e produtividade. Brasília: MDA, 1992. 180p.

CALVET, S.; CAMBRA-LÓPEZ, M.; BLANES-VIDAL, V.; ESTELLÉS, F.; TORRES, A.G. Ventilation rates in mechanically-ventilated commercial poultry buildings in Southern Europe: measurement system development and uncertainty analysis. Biosystems Engineering, v.30, p.423-432, 2010.

CAMBARDELLA, C.A.; MOORMAN, T.B.; NOVAK, J.M.; PARKIN, T.B.; KARLEN, D.L.; TURCO, R.F.; KONOPKA, A.E. Field scale variability of soil properties in Central Iowa soils. Soil Science Society of America Journal, v.58, p.1501-1511, 1994.

COBB-VANTRESS BRASIL. Manual de manejo de frangos de corte. Guapiaçu: Cobb Vantress, 2008. 66p.

CRESSIE, N.A.C. Statistics for spatial data. New York: John Wiley, 1993. 900p.

DAO, T.H.; ZHANG, H. Rapid composition and source screening of heterogeneous poultry litter by x-ray fluorescence spectrometry. Annals of Environmental Science, v.1, p.69-79, 2007.
ELLIOT, H.A.; COLLINS, N.E. Factors affecting ammonia release in broiler houses. Transactions of ASAE, v.25, p.413-424, 1982.

GALLO, B.B. Penumbra: a tecnologia Dark House e suas características. Revista Produção Animal - Avicultura, n.26, p.30-33, 2009.

GLOBALGAP. Pontos de controle e critérios de cumprimento: garantia integrada da fazenda - aves. Cologne: GLOBALGAP, 2007. 22p.

GOLDEN SOFTWARE. Surfer mapping system. Version 9. Golden: Golden Software, 2009.

GONZÁLES, E.; SALDANHA, E.S.P.B. Os primeiros dias de vida do frango e a produtividade futura. In: CONGRESSO BRASILEIRO DE ZOOTECNIA, 11.; CONGRESSO INTERNACIONAL DE ZOOTECNIA, 3., 2001, Goiânia. Anais. Goiânia: Universidade Católica de Goiás, 2001. p.310-327.

HERNANDES, R.; CAZETTA, J.O. Método simples e acessível para determinar amônia liberada pela cama aviária. Revista Brasileira de Zootecnia, v.30, p.824-829, 2001.

HERNANDES, R.; CAZETTA, J.O.; MORAES, V.M.B. de. Frações nitrogenadas, glicídicas e amônia liberada pela cama de frangos de corte em diferentes densidades e tempos de confinamento. Revista Brasileira de Zootecnia, v.31, p.1795-1802, 2002.

JONES, E.K.M.; WATHES, C.M.; WEBSTER, A.J.F. Avoidance of atmospheric ammonia by domestic fowl and the effect of early experience. Applied Animal Behaviour Science, v.90, p.293-308, 2005.

KELLEHER, B.P.; LEAHY, J.J.; HENIHAN, A.M.; O'DWYER, T.F.; SUTTON, D.; LEAHY, M.J. Advances in poultry litter disposal technology - a review. Bioresource Technology, v.83, p.27-36, 2002.

MANNING, L.; CHADD, S.A.; BAINES, R.N. Key health and welfare indicators for broiler production. Worlds Poultry Science Journal, v.63, p.46-62, 2007.

MILES, D.M.; OWENS, P.R.; ROWE, D.E. Spatial variability of litter gaseous flux within a commercial broiler house: ammonia, nitrous oxide, carbon dioxide, and methane. Poultry Science, v.85, p.167-172, 2006.

MILES, D.M.; ROWE, D.E.; OWENS, P.R. Winter broiler litter gases and nitrogen compounds: temporal and spatial trends. Atmospheric Environment, v.42, p.3351-3363, 2008.

OLIVEIRA, J.E. de; SAKOMURA, N.K.; FIGUEIREDO, A.N.; LUCAS JÚNIOR, J. de; SANTOS, T.M.B. dos. Efeito do isolamento térmico de telhado sobre o desempenho de frangos de corte alojados em diferentes densidades. Revista Brasileira de Zootecnia, v.29, p.1427-1434, 2000.

OLIVEIRA, M.C. de; ALMEIDA, C.V.; ANDRADE, D.O.; RODRIGUES, S.M.M. Teor de matéria seca, $\mathrm{pH}$ e amônia volatilizada da cama de frango tratada ou não com diferentes aditivos. Revista Brasileira de Zootecnia, v.32, p.951-954, 2003.

OWADA, A.N.; NÄÄS, I. de A.; MOURA, D.J. de; BARACHO, M. dos S. Estimativa de bem-estar de frango de corte em função da concentração de amônia e grau de luminosidade no galpão de produção. Engenharia Agrícola, v.27, p.611-618, 2007. 
QIU, G.; GUO, M. Quality of poultry litter-derived granular activated carbon. Bioresource Technology, v.101, p.379-386, 2010.

ROBERTSON, G.P. GS+ geostatistics for the environmental sciences. Version 7. Plainwell: Gamma Desing Software, 2008.

SAS INSTITUTE. The statistical analysis system for Windows. Version 9. Cary: SAS Institute, 2002.

TASISTRO, A.S.; KISSEL, D.E.; BUSH, P.B. Spatial variability of broiler litter composition in a chicken house. Journal of Applied Poultry Research, v.13, p.29-43, 2004.

TRALDI, A.B.; OLIVEIRA, M.C. de; DUARTE, K.F.; MORAES, V.M.B. de. Avaliação de probióticos na dieta de frangos de corte criados em cama nova ou reutilizada. Revista Brasileira de Zootecnia, v.36, p.660-665, 2007.
VIEIRA, S.R. Geoestatística em estudos de variabilidade espacial do solo. In: NOVAIS, R.F. de; ALVAREZ V., V.H.; SCHAEFER, C.E.G.R. (Ed.). Tópicos em ciência do solo. Viçosa: Sociedade Brasileira de Ciência do Solo, 2000. p.1-53.

WARRICK, A.W.; NIELSEN, D.R. Spatial variability of soil physical properties in the field. In: HILLEL, D. (Ed.). Applications of soil physics. New York: Academic, 1980. p.319-344.

WEAVER JUNIOR, W.D.; MEIJERHOF, R. The effect of different levels of relative humidity and air movement on litter conditions, ammonia levels, growth, and carcass quality for broiler chickens. Poultry Science, v.70, p.746-755, 1991.

Recebido em 17 de agosto de 2010 e aprovado em 28 de fevereiro de 2011 